\title{
Consideration of health literacy in implementation science
}

www.cambridge.org/cts

\section{Implementation, Policy and Community Engagement Perspective}

Cite this article: Han H-R, Wu D, Taylor J, Wright R, and Abshire M. Consideration of health literacy in implementation science. Journal of Clinical and Translational Science 5: e118, 1-2. doi: $10.1017 /$ cts.2021.775

Received: 28 December 2020

Revised: 17 March 2021

Accepted: 24 March 2021

\section{Keywords:}

Health literacy; evidence-based practice; implementation science; stakeholders

\section{Address for correspondence:}

H.-R. Han, PhD, RN, FAAN, Johns Hopkins School of Nursing, 525 N. Wolfe Street, Baltimore, MD 21205, USA.

Email: hhan3@jhu.edu
(C) The Author(s), 2021. Published by Cambridge University Press on behalf of The Association for Clinical and Translational Science. This is an Open Access article, distributed under the terms of the Creative Commons Attribution licence (http://creativecommons.org/licenses/ by/4.0/), which permits unrestricted re-use, distribution, and reproduction in any medium, provided the original work is properly cited.

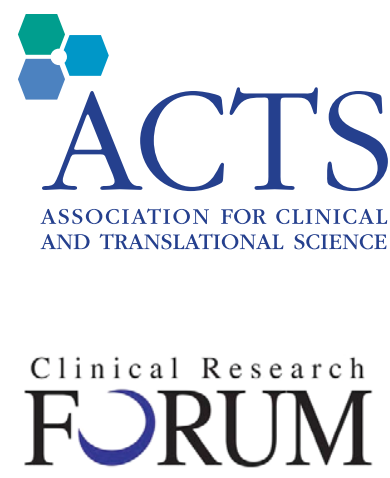

Analysis. Advocacy. Action.
Hae-Ra Han ${ }^{1,2}$, , Deborah $W^{1}{ }^{1}$ Janiece Taylor ${ }^{1}$, Rebecca Wright ${ }^{1}$ and

Martha Abshire ${ }^{1}$ (1)

${ }^{1}$ Johns Hopkins School of Nursing, Baltimore, MD, USA and ${ }^{2}$ Johns Hopkins Bloomberg School of Public Health, Baltimore, MD, USA

It has been widely stated that evidence-based practices (EBPs) take on average 17 years to be incorporated into routine clinical practice, with only about half of EBPs ever reaching widespread clinical adoption [1,2]. There is a growing interest in shortening the time lag between health research and translation into routine care for a public health impact. Implementation science is the scientific study of strategies to promote the uptake of research findings and other EBPs into real-world, general clinical practice with sustained public health benefits $[3,4]$. Broader than traditional clinical research in scope, implementation science requires involvement of diverse stakeholders who are not routinely part of clinical trials. In particular, health system stakeholders, including affected communities and operational partners such as administrators or health system managers and frontline health workers are key players in the conduct of implementation research projects [5]. Nevertheless, due to diverse educational backgrounds, clinical experiences, and expertise, bringing together these stakeholders often presents a critical challenge. Clear communication is an essential part of promoting a collaborative effort, and understanding health literacy can be a catalyst to address this challenge.

The Institute of Medicine report, Health Literacy: A Prescription to End Confusion, defines health literacy as "the degree to which individuals have the capacity to obtain, process, and understand basic health information and services needed to make appropriate health decisions [6]." More recent definitions focus on specific skills needed to navigate the health system and the importance of clear communication between health care providers and their patients [7]. The US Department of Education's 2003 National Assessment of Adult Literacy - the most comprehensive assessment of adult literacy and the first-ever national assessment of health literacy [8] - revealed that only 12 percent of US adults are proficient enough in health literacy to understand and use printed health information effectively [9]; more than a third of US adults are in the "basic" or "below basic" health literacy groups, which means they may fail to understand most health information. Adding to these challenges, twenty-five million Americans (8.7 percent) have limited English proficiency [10]. There is a strong association between limited English proficiency and low health literacy $[11,12]$. Taken together, these statistics underscore the relevance of health literacy within implementation science, which requires clear communication to develop shared understanding among increasingly diversifying stakeholders as key players in the design and conduct of the research - patients, caregivers, frontline clinicians, administrators, and researchers.

We conducted a scoping review to better understand how published implementation science studies have addressed health literacy. A PubMed search was done to identify articles published from the inception through December 22, 2020 in English. We used broad search terms, "health literacy" and "implementation science" to identify potential articles in which both topics were addressed. The search resulted in a total of 18 articles; more than two-thirds $(n=14)$ were published in the last 5 years. The articles identified discussed a variety of interventions across different health conditions including HIV, cancer, mental illnesses, hypertension, diabetes, spinal cord injuries, and sickle cell disease. Health literacy was incorporated in one of three ways: (1) as a consideration when developing interventions, (2) as a factor in successful implementation of interventions, or (3) as an outcome the intervention sought to impact. The degree to which health literacy was incorporated, however, varied and was rarely a focal point.

We found three of the articles, which exemplified future directions for the integration of health literacy in implementation science. Specifically, Bohkhour et al. [13], Davis et al. [14], and Houston et al. [15] observed greater pre- and postintervention improvements in subgroups of participants with initially lower health literacy scores (measured at baseline using either Rapid Estimate of Adult Literacy in Medicine or Short Test of Functional Health Literacy). These three articles not only acknowledged the role of health literacy in successful intervention implementation but also sought to improve health literacy by incorporating it into the intervention design in a manner that tailors information appropriately to the population of interest. By stratifying outcome data according to health literacy scores, health literacy could be analyzed as a factor for successful implementation for achieving improved health outcomes. 
Additional opportunities for addressing health literacy include understanding the role of health literacy in the implementation setting, where confusion and misunderstanding are likely to occur. One of the most popular implementation research frameworks, the Consolidated Framework for Implementation Research [16], offers multiple implementation contexts to consider for implementation of health interventions. One of them is the "inner setting" of organizations, which addresses characteristics and features of the implementing organization, and has been closely associated with implementation outcomes and the quality of care $[17,18]$. For example, how healthcare systems address varying levels of health literacy of their patients is called organizational health literacy [7]. There is a growing appreciation that health literacy is the byproduct of the demands that health systems or organizations place on individuals and the specific healthcare system where care is provided or health interventions are implemented. A health literate organization is an ideal setting to conduct an implementation research project as health literacy is a value and actively promoted mission within the organization [7]. Future implementation research should consider organizational health literacy as one of the key inner setting characteristics and at minimum, incorporate adequate assessment tools (e.g., Health literate healthcare organization 10-item questionnaire [19]) as part of the evaluation plan.

Healthcare environments around the world are increasingly dynamic, resource-constrained, and interconnected - and are driven by equally complex political and economic environments. Accordingly, maximizing healthcare value has become a policy imperative globally [20]. To this end, implementation science will become even more critical for promoting value-based health programs. As the focus on implementation science continues, health literacy can serve as an innovative and disruptive force that creates a new value equation for EBPs and implementation science.

Acknowledgments. This was funded, in part, by grants from the NIH NCATS Johns Hopkins Institute for Clinical and Translational Research [UL1TR003098], National Institute of Nursing Research [P30NR018093], and National Institute on Aging [R01AG062649] to HRH.

Disclosures. The authors have no conflicts of interest to declare.

\section{References}

1. Morris ZS, Wooding S, Grant J. The answer is 17 years, what is the question: understanding time lags in translational research. Journal of the Royal Society of Medicine 2011; 104(12): 510-520. doi: 10.1258/jrsm.2011. 110180.

2. Balas EA, Boren SA. Managing clinical knowledge for health care improvement. Yearbook of Medical Informatics 2000; (1) 65-70. PMID: 27699347.

3. Woolf SH. The meaning of translational research and why it matters. JAMA 2008; 299(2): 211-213. doi: 10.1001/jama.2007.26.

4. Eccles MP, Mittman BS. Welcome to implementation science. Implementation Science 2006; 1: 1. doi: 10.1186/1748-5908-1-1.

5. Bauer MS, Damschroder L, Hagedorn H, Smith J, Kilbourne AM. An introduction to implementation science for the non-specialist. $B M C$ Psychology 2015; 3(1): 32. doi: 10.1186/s40359-015-0089-9.
6. Institute of Medicine (US) Committee on Health Literacy. Health Literacy: A Prescription to End Confusion. Nielsen-Bohlman L, Panzer AM, Kindig DA, editors. Washington, DC: National Academies Press (US), 2004

7. Brach C, Keller D, Hernandez LM, et al. Ten attributes of health literate health care organizations [Internet], 2012 [cited Nov 27, 2020]. (https:// nam.edu/wp-content/uploads/2015/06/BPH_Ten_HLit_Attributes.pdf)

8. Centers for Disease Control and Prevention. Health literacy [Internet], 2020 [cited March 11, 2021]. (https://www.cdc.gov/healthliteracy/ researchevaluate/measure-peoples-skills-experiences.html)

9. US Department of Health and Human Services. America's health literacy: why we need accessible health information [Internet], 2019 [cited Nov 23, 2020]. (https://wayback.archive-it.org/5774/20190103020246/https://health. gov/communication/literacy/issuebrief/)

10. US Census Bureau. Detailed languages spoken at home and ability to speak English for the population 5 years and over: 2009-2013 [Internet], 2015 [cited Nov 20, 2020]. (https://www.census.gov/data/tables/2013/demo/ 2009-2013-lang-tables.html)

11. Sentell T, Braun KL. Low health literacy, limited English proficiency, and health status in Asians, Latinos, and other racial/ethnic groups in California. Journal of Health Communication 2012; 17 (Suppl 3): 82-99. doi: 10.1080/10810730.2012.712621.

12. Feinberg I, O'Connor MH, Owen-Smith A, Ogrodnick MM, Rothenberg $\mathbf{R}$. The relationship between refugee health status and language, literacy, and time spent in the United States. Health Literacy Research and Practice 2020; 4(4): e230-e236. doi: 10.3928/2474830720201109-01.

13. Bokhour BG, Fix GM, Gordon HS, et al. Can stories influence AfricanAmerican patients' intentions to change hypertension management behaviors? A randomized control trial. Patient Education and Counseling 2016; 99(9): 1482-1488. doi: 10.1016/j.pec.2016.06.024.

14. Davis K, Swarbrick P, Krzos IM, Ruppert S, O'Neill S. Health literacy training: a model for effective implementation and sustainability. Psychiatric Rehabilitation Journal 2015; 38(4): 377-379. doi: 10.1037/ prj0000166.

15. Houston TK, Fix GM, Shimada SL, et al. African American veterans storytelling: a multisite randomized trial to improve hypertension. Medical Care 2017; 55 Suppl 9 (Suppl 2): S50-S58. doi: 10.1097/MLR. 0000000000000766.

16. Damschroder LJ, Aron DC, Keith RE, Kirsh SR, Alexander JA, Lowery JC. Fostering implementation of health services research findings into practice: a consolidated framework for advancing implementation science. Implementation Science 2009; 4: 50. doi: 10.1186/1748-5908-4-50.

17. Keith RE, Crosson JC, O'Malley AS, Cromp D, Taylor EF. Using the Consolidated Framework for Implementation Research (CFIR) to produce actionable findings: a rapid-cycle evaluation approach to improving implementation. Implementation Science 2017; 12(1) :15. doi: 10.1186/s13012017-0550-7.

18. Bonaccorsi G, Romiti A, Lerardi F, et al. Health-literate healthcare organizations and quality of care in hospitals: a cross-sectional study conducted in Tuscany. International Journal of Environmental Research and Public Health 2020; 17(7): 2508. doi: 10.3390/ijerph17072508.

19. Kowalski C, Lee SY, Schmidt A, et al. The health literate health care organization 10 item questionnaire (HLHO-10): development and validation. BMC Health Services Research 2015; 15: 47. doi: 10.1186/s12913-0150707-5.

20. Berwick DM, Nolan TW, Whittington J. The triple aim: care, health, and cost. Health Affairs 2008; 27(3): 759-769. doi: 10.1377/hlthaff.27.3.759. 